\title{
Characterization of Humic Substances by Functional Groups and Spectroscopic Methods
}

\author{
M. Eshwar ${ }^{1 *}$, M. Srilatha ${ }^{1}$, K. Bhanu Rekha ${ }^{2}$ and S. Harish Kumar Sharma ${ }^{1}$ \\ ${ }^{1}$ Department of Soil Science and Agricultural chemistry, College of Agriculture, PJTSAU, \\ Rajendranagar, Hyderabad- 500 030, Telangana, India \\ ${ }^{2}$ Department of Agronomy, Agriculture College, Palem, Nagarkurnool \\ *Corresponding author
}

\section{A B S T R A C T}

\section{Keywords}

Humic acid (HA), Fulvic acid (FA),

Functional groups (total acidity, carboxyl group and phenolic$\mathrm{OH}$ group) E4/E6 ratio and UV spectra.

Article Info

Accepted:

17 September 2017

Available Online:

10 October 2017
The present study was carried in the Department of Soil Science and Agricultural Chemistry, College of Agriculture, Rajendranagar. The humic and fulvic acids were extracted, isolated and purified from manures and were studied for their functional groups and spectroscopic methods. It has been found that the total acidity $\left(9.4 \mathrm{me} \mathrm{g}^{-1}\right)$, carboxyl group (6.2 $\left.\mathrm{me} \mathrm{g}^{-1}\right)$ and phenolic-OH $\left(3.2 \mathrm{me} \mathrm{g}^{-1}\right)$ groups were higher in case of fulvic acid compared to humic acid (7.2, 4.2 and $3.0 \mathrm{me} \mathrm{g}^{-1}$ respectively). Among these functional groups, the percent contribution of carboxylic groups towards total acidity was higher than that of phenolic-OH groups in both humic fractions. The ratio of optical densities at 465 and $665 \mathrm{~nm}$ i.e. $\mathrm{E}_{4} / \mathrm{E}_{6}$ ratio was higher in case of fulvic acid (6.17) compared to humic acid (4.34). The UV spectra of humic and fulvic acid were similar in nature in spite of the differences in their composition and showed a decreasing optical density with increasing wavelength.

\section{Introduction}

Humic substances are often described as coiled, long chain molecules of two or three dimensional cross linked macromolecules which may vary in molecular weight depending on type of humic acid and method of measurement (Stevenson, 1994). They form the largest fraction of soil organic matter $(\mathrm{OM})$ and play vital role in improving soil productivity. On account of their wide range of molecular sizes and properties, humic substances are usually fractionated to obtain materials with similar properties. The three fractions of humic substances are: i) fulvic acid (FA), (ii) humic acid (HA) and (iii) humin. Among these humic fractions, FA is soluble in both acid and alkali. HA is the fraction which is soluble only in alkali. The most insoluble fraction of humus is humin, which is neither soluble in acid nor alkali.

Soil organic matter fractions are capable of forming complexes with metal ions. The ability of humic substances to form stable complexes with metal ions can be accounted for their high content of oxygen containing functional groups viz., carboxylic, phenolic aliphatic and alcoholic - $\mathrm{OH}$ groups. As these complex formation reactions between metal 
ions and humic substances are helpful in understanding the problems of plant nutrition (Stevenson et al., 1993). During complexation, numerous compounds including humic acid (HA) and fulvic acid (FA) are involved which control the distribution and supply of micronutrients to plants and interact with metal ions through their functional groups forming metal complexes of varying stabilities.

The spectroscopic studies of humic compounds have been the focus of researchers in the recent past. The humicfulvic acids have been extensively characterized by UV-VIS spectroscopy. Schnitzer (1977) studied that HAs and FAs extracted from soils formed under different geographic and pedologic environments had similar analytical characteristics and chemical structures. The colour of humic substances is an important physical property, which is used to characterize humic fractions of soil (Tan and Van Schuylenborgh 1961; Kononova 1966; Schnitzer 1971; Flaig 1975). The colour ratio is used as an index for the rate of light absorption in the visible range. Absorption of humic acid in the ultraviolet range is based on the aromatic groups that contribute to the molecular structure, i.e. the sum of phenyl propane units, and on several chromophoric structural elements. The evidence for the complexation of micronutrient metal ions with humic acid (HA) and fulvic acid (FA) has been demonstrated by several workers employing chemical methods and IR spectroscopy (Sujana Reddy et al., 1998; Stevenson et al., 1993 and Schnitzer and Hansen, 1970). The studies on the interactions of metal ions with humic acids extracted from the soils of Hyderabad have been reported earlier (Sailaja, 1999 and Srilatha, 2001).

\section{Materials and Methods}

The present study was carried out at the laboratory for characterization of humic substances by functional groups and UV spectra at department of Soil Science and Agricultural Chemistry, College of Agriculture, Rajendranagar in the year 201617.

\section{Characterisation of humic substances}

Humic acid and Fulvic acids extracted from manures were used for this study and characterized for their functional groups and spectral analysis.

\section{Determination of functional groups}

\section{Total acidity}

Total acidity in HA/FA was determined by Ba $(\mathrm{OH})_{2}$ method. Wright and Schnitzer (1961) applied this method for humic substances. In the modified procedure of Schnitzer and Gupta (1965), the sample is allowed to react with an excess of $\mathrm{Ba}(\mathrm{OH})_{2}$, the unreacted $\mathrm{Ba}$ $(\mathrm{OH})_{2}$ could be determined by back titration with standard acid.

\section{$\mathrm{Ba}(\mathrm{OH})_{2}+2 \mathrm{HA} \longrightarrow \mathrm{Ba} \mathrm{A}_{2}+2 \mathrm{HOH}(\mathrm{I})$}

Fifty milligrams of HA/FA along with blank was taken in separate stoppered flasks and20 mlof $0.2 \mathrm{~N} \mathrm{Ba}(\mathrm{OH})_{2}$ was added. The flasks were shaken for $24 \mathrm{~h}$ at room temperature. The suspension was filtered and the residue was washed with $\mathrm{CO}_{2}$ free distilled water. The filtrate and washings were titrated against $0.5 \mathrm{~N} \mathrm{HCl}$ to $\mathrm{pH} 8.4$ potentiometricaily. Identical blanks were maintained simultaneously.

(TV for blank - TV for sample) $\mathrm{X}$ Normality of acid x 1000

Total acidity $=$

(me $\mathrm{g}^{-1}$ ) Weight of sample (mg)

Where

TV - Titre Value 


\section{Carboxylgroups}

HA / FA were treated with calcium acetate, acetic acid liberated is titrated with standard $0.1 \mathrm{NNaOH}$ (Schnitzer and Khan, 1972).

$2 \mathrm{R}-\mathrm{COOH}+\left(\mathrm{CH}_{3} \mathrm{COO}\right)_{2} \mathrm{Ca}$ $\longrightarrow(\mathrm{RCOO})_{2} \mathrm{Ca}+2 \mathrm{CH}_{3} \mathrm{COOH}-$ (II)

For this, fifty milligrams of HA/FA was taken in a stoppered flask to which $10 \mathrm{ml}$ of 1 $N\left(\mathrm{CH}_{3} \mathrm{COO}\right)_{2} \mathrm{Ca}$ and $40 \mathrm{ml}$ of $\mathrm{CO}_{2}$ free distilled water were added. A blank was also set up simultaneously. After shaking at room temperature for $24 \mathrm{~h}$ the suspension was filtered and the residue was washed with $\mathrm{CO}_{2}$ free distilled water. The filtrate and washings were titrated potentiometrically with standard $0.1 \mathrm{NNaOH}$ to $\mathrm{pH} 9.8$.

(TV for sample-TV for blank) $\mathrm{x}$

Normality of base $(0.1 N)$ x 1000 $\mathrm{COOH}$ groups $=$

$\left(\mathrm{me} \mathrm{g}^{-1}\right)$ Weight of sample (mg)

\section{Phenolic-OH groups}

The phenolic-OH groups were calculated as the difference between total acidity and carboxylic group acidity.

Phenolic-OH groups $=($ Total acidity $)$ $\left(-\mathrm{COOH}\right.$ acidity) $\left(\mathrm{me} \mathrm{g}^{-1}\right)\left(\mathrm{me} \mathrm{g}^{-1}\right)\left(\mathrm{me} \mathrm{g}^{-1}\right)$

\section{Spectral Characteristics}

\section{$\mathbf{E}_{4} / \mathrm{E}_{6}$ ratios}

Fifteen milligrams of HA/FA were dissolved in $200 \mathrm{ml}$ of Std. $0.1 \mathrm{~N} \mathrm{NaOH}$ (Kononova, 1966) and the optical densities were measured at 465 and $665 \mathrm{~nm}$ on a UV-visible spectrophotometer. The ratios of optical densities at 465 and $665 \mathrm{~nm}$ were calculated and were expressed as $\mathrm{E}_{4} / \mathrm{E}_{6}$ ratios.

\section{UV-spectra of humic acid/fulvic acids}

Spectral characteristics of HA/FA were evaluated in UV- range in the wavelength range of 200 to $300 \mathrm{~nm}$.

For this purpose, the solution containing 10 $\mathrm{mg} \mathrm{HA} / \mathrm{FA} \mathrm{ml}^{-1}$ of distilled water was prepared and the absorbance was recorded on a UV-visible spectrophotometer.

\section{Results and Discussion}

\section{Total acidity}

The total acidity of humic acid was $7.2 \mathrm{me} \mathrm{g}^{-1}$ that of fulvic acid $9.4 \mathrm{me} \mathrm{g}^{-1}$ indicating that fulvic acid has high total acidity than humic acid (Table 1).

Functional groups obtained from humic and fulvic acids are similar to those obtained by Ramalakshmi (2011).

Banik and Sanyal (2006) also reported high total acidity in case of fulvic acid over humic acid. Srilatha (2014), Sanyal (2002) and Sujana Reddy and Rao (2000) observed that increase in total acidity with decreasing molecular weight was in consistence with increasing degree of oxidation of low molecular weight fractions.

\section{Carboxyl groups}

The carboxyl group contents of humic acid was $4.2 \mathrm{me} \mathrm{g}^{-1}$ and fulvic acid was $6.2 \mathrm{me} \mathrm{g}^{-1}$ respectively. Higher content of carboxyl groups in fulvic acid may be due to their low particle weight because decarboxylation did not scan before polymerization or condensation due to high molecular weight thus indicating degradation of humic acid which may also result in high content of carboxyl groups (Srilatha et al., 2013 and Lal and Mishra, 2000). 


\section{Phenolic-OH groups}

The phenolic-OH group contents of fulvic acid was $3.2 \mathrm{me} \mathrm{g}^{-1}$ while it was $3.0 \mathrm{me} \mathrm{g}^{-1}$ in humic acid. From the close perusal of data on functional groups it was observed that higher content of carboxyl groups in both humic acid and fulvic acid than phenolic-OH groups suggesting that the carbohydrates and phenolic compounds produced were easily degradable and thus readily converted to carboxyl groups on subsequent oxidation. These results are in accordance with the findings of Satisha and Devarajan (2011), Erdogan et al., (2007) and Banik and Sanyal (2006).
From the data, percent contribution of carboxylic groups and phenolic - $\mathrm{OH}$ groups were also calculated (Table 2). The data indicated higher percent contribution of (carboxylic group) - $\mathrm{COOH}$ group towards total acidity than that of phenolic-OH groups. The percent contribution of $-\mathrm{COOH}$ groups in humic acid was lower $(58.3 \%)$ than fulvic acid $(65.9 \%)$. The percent contribution of phenolic-OH groups towards total acidity was $(41.6 \%)$ and $(34.0 \%)$ in humic acid and fulvic acid respectively. The acidity of fulvic acid was predominantly due to carboxyl groups whereas phenolic-OH groups contributed to nearly one third of the total acidity (Pandeya and Singh, 2000).

Fig.1 UV spectra of humic acid

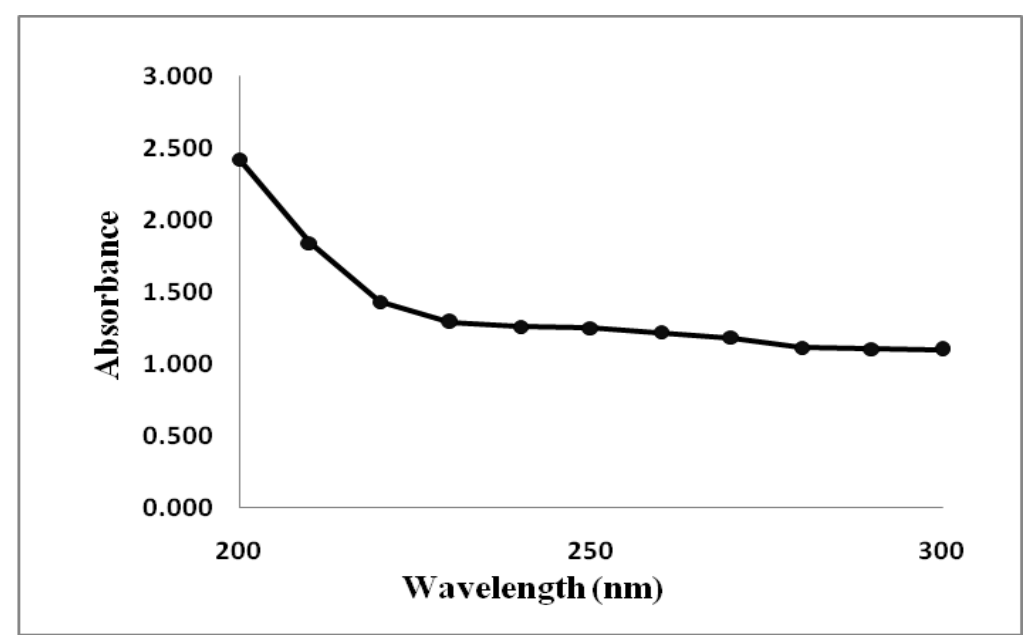

Fig.2 UV spectra of fulvic acid

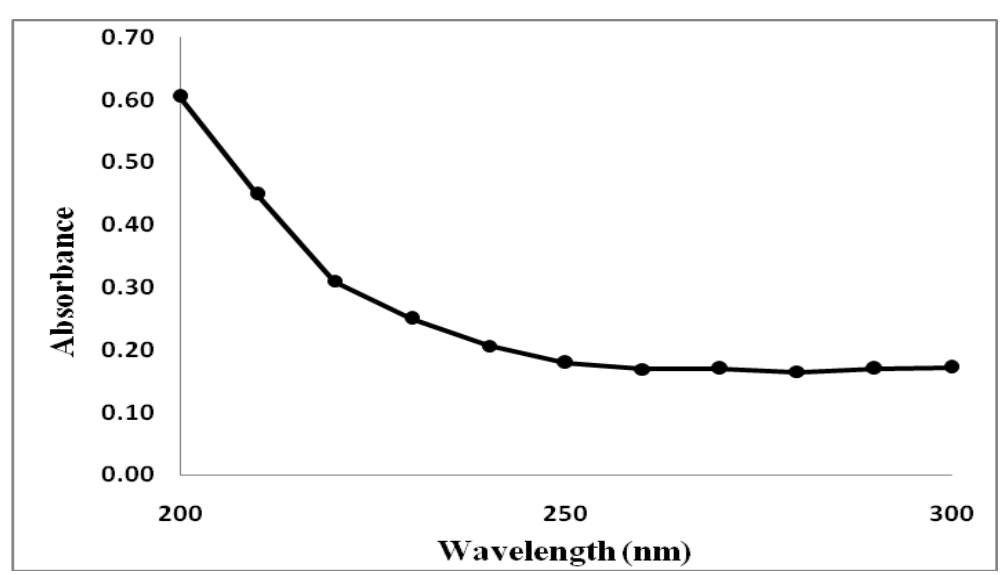


Table.1 Functional group (total acidity, carboxyl, phenolic-OH and $\mathrm{E}_{4} / \mathrm{E}_{6}$ ) contents of Humic and fulvic acids

\begin{tabular}{|c|c|c|c|c|}
\hline $\begin{array}{c}\text { Humic } \\
\text { substances }\end{array}$ & $\begin{array}{c}\text { Total acidity } \\
\left(\mathbf{m e ~}^{-\mathbf{1}}\right)\end{array}$ & $\begin{array}{c}\text { Carboxylic groups } \\
\left(\mathbf{m e ~}^{-\mathbf{1}}\right)\end{array}$ & $\begin{array}{c}\text { Phenolic groups } \\
\left(\mathbf{m e ~}_{\mathbf{~}}^{\mathbf{- 1}}\right)\end{array}$ & $\mathbf{E}_{\mathbf{4}} / \mathbf{E}_{\mathbf{6}} \mathbf{r a t i o}$ \\
\hline Humic acid & 7.2 & 4.2 & 3.0 & 4.34 \\
\hline Fulvic acid & 9.4 & 6.2 & 3.2 & 6.17 \\
\hline
\end{tabular}

Table. 2 Content of carboxyl and phenolic-OH groups (expressed as \% Total acidity) of Humic and fulvic acids

\begin{tabular}{|l|c|c|}
\hline Functional groups & $\begin{array}{c}\text { Humic acid } \\
\text { (\% Total acidity) }\end{array}$ & $\begin{array}{c}\text { Fulvic acid } \\
\text { (\% Total acidity) }\end{array}$ \\
\hline Carboxyl groups & 58.33 & 65.95 \\
\hline Phenolic-OH groups & 41.66 & 34.04 \\
\hline
\end{tabular}

\section{$\mathbf{E}_{4} / \mathbf{E}_{6}$ ratio}

The ratio of optical densities at 465 and 665 $\mathrm{nm}$ is used for characterization of humic and fulvic acids. The relationship $\mathrm{E}_{4} / \mathrm{E}_{6}$ is related to aromacity and degree of condensation of the chain of aromatic carbons of humic substances, and could be used as a humification index (Srilatha et al., 2013, Stevenson, 1982 and Schnitzer and Khan, 1972). This ratio is referred to as $E_{4} / E_{6}$ ratio (Lal and Mishra, 1999) is independent of concentration of humic and fulvic acids but varies with humic material extracted from different soil types (Tahiri et al., 2016 and Sailaja and Rao, 2000).

The $\mathrm{E}_{4} / \mathrm{E}_{6}$ ratio of humic acid was4.34 that of fulvic acid was 6.17 (Table 1) and it could be observed from the data that the fulvic acid had higher $\mathrm{E}_{4} / \mathrm{E}_{6}$ ratio in comparison to the humic acid. It could be due to the higher degree of aromaticity in carbon atoms of humic acid. Tahiri et al., (2016), Srilatha et al., (2013) and Satisha and Devarajan (2011) also reported slightly higher $\mathrm{E}_{4} / \mathrm{E}_{6}$ ratio of fulvic acid than humic acid.

A low ratio of $\mathrm{E}_{4} / \mathrm{E}_{6}<5.0$ indicates high degree of condensation of aromatic humic components, high molecular weight and low acidity which are characteristics of humic acid fraction where as high $\mathrm{E}_{4} / \mathrm{E}_{6}$ ratio of fulvic acid reflects a low degree of aromatic condensation and presence of a relatively large proportion of aliphatic structure. These results are in line with those of Haddad et al., (2015), Petrus et al., (2009) and Banik and Sanyal (2006).

\section{UV Spectra}

The UV spectra of humic and fulvic acid was in the range of 200 to $300 \mathrm{~nm}$ with a decreasing optical density and increasing wavelength (Figs. 1 and 2). The UV spectra of humic and fulvic acid were similar in nature in spite of the differences in their composition. The absorbance of light in UV range was due to the presence of multiple bonds and due to unshared electronic pair in the organic molecule. These groups which confer colour to the humic substances are called chromophores. The typical chromophores that are known to occur in humic acid are $\mathrm{C}=\mathrm{C}$ and $\mathrm{C}=\mathrm{O}$ groups (Stevenson, 1982). Lack of absorbance in UV range could be due to the fact that the humic substances are considered to be an intermediate stage of development between 
lignin and coal (Srilatha, 2014; Ramalakshmi et al., 2013; Sailaja and Rao, 2000 and Stevenson, 1982).

From the data it is evident that total acidity, carboxyl group and phenolic-OH group were higher in case of fulvic acid compared to humic acid. The increase in total acidity with decreasing molecular weight was in consistence with increasing degree of oxidation of low molecular weight humic fractions. Higher content of carboxyl groups in fulvic acid may be due to their low particle weight because decarboxylation did not scan before polymerization or condensation. The acidity of fulvic acid was predominantly due to carboxyl groups whereas phenolic-OH groups contributed to nearly one third of the total acidity. The UV spectra of humic and fulvic acid were similar in nature in spite of the differences in their composition. The humification index $\left(\mathrm{E}_{4} / \mathrm{E}_{6}\right.$ ratio) of fulvic acid is higher than humic acid.

\section{References}

Banik, G.C., and Sanyal, S.K. 2006. A study on chromium-humic complexation: Part 1. Characterization of humic Substances. Journal of the Indian Society of Soil Science. 54 (2): 163-169.

Erdogan, S., Baysal, A., Akba, O and Hamamci, C 2007.Interaction of metals with humic acid isolated from oxidized coal. Polish Journal of Environmental Studies. 16 (5): 671-675.

Flaig, W., Beutelspacher, $\mathrm{H}$ and Rietz, E. 1975.Chemical composition and physical properties of humic substances. In Soil Components, Vol. 1 Inorganic Components (J.E. Gieseking, Ed.), Springer-Verlag, New York, pp. 1-211.

Haddad, G., Ali, F.E and Mouneimne, A.H 2015. Humic matter of compost: determination of humic spectroscopic ratio $\left(\mathrm{E}_{4} / \mathrm{E}_{6}\right)$. Current Science International. 4 (1): 56-72.

Kononova, M.M., 1966. Soil Organic Matter. Press. Pp. 400-410.

Lal, J.K., and Mishra, B 2000. Physico-chemical characterization of humic substances isolated from some soil series. Journal of Research. 12 (2): 179-185.

Lal, J.K., and Mishra, B.1999. Visible absorption spectroscopic investigation of soil humic substances. Journal of Research. 11 (2): 135-140.

Pandeya, S.B., and Singh, A.K. 2000. Potentiometric measurement of stability constants of complexes between fulvic and carboxylate and $\mathrm{Fe}^{3+}$.Plant and Soil. 223: 13-21.

Petrus, A.C., Ahmed, O.H and Muhammad, A.M.N 2009.Chemical characteristics of compost and humic acid from sago wastes. American Journal of Applied Science. 6 (11): 188-1884.

Ramalakshmi, Ch. S., 2011. Vermicomposting for effective waste management and its evaluation under INM rice-pulse cropping system. Ph.D. (Ag.) thesis submitted to Acharya N.G. Ranga Agricultural University, Rajendranagar, Hyderabad.

Ramalakshmi, Ch. S., Rao, P.C., Sreelatha, T., Padmaja, G and Madhavi, M 2013. Nitrogen use efficiency and production efficiency of rice under integrated nutrient management. Journal of Rice Research. 4 (1\&1): 42-59.

Sailaja, M., 1999. Interactions between metal ions and humic fractions extracted from an Alfisol and Vertisol in relation to their plant availability, M.Sc. (Ag.) thesis submitted to Acharya NG Ranga Agricultural University, Hyderabad.

Sanyal, S.K., 2002. Colloid chemical properties of soil humic substances: A relook. Bulletin of the Indian Society of Soil Science. 21: 278307.

Satisha, G.C., and Devarajan, L 2011. Composition and characterization of humic substances extracted from effluent-based pressmud composts. Agropedology. 21 (1): 8-17.

Schnitzer, M., 1971. Characterization of humic constituents by spectroscopy. In Soil Biochemistry (A.D. McLaren and J. Skujins, Eds.), Vol. 2, Marcel Dekker, New York, pp. 60-95.

Schnitzer, M., 1977. Recent findings on the characterization of humic substances 
extracted from soils from widely differing climatic zones. In Soil Organic Matter Studies. International Atomic Energy Agency, Vienna, II, pp. 117-132.

Schnitzer, M., and Gupta, U.C 1965. Determination of acidity in soil organic matter. Soil Science Society of America Proceedings. 29: 274-277.

Schnitzer, M., and Hansen, E.H 1970. Organometallic interactions in soils: 8. an evaluation of methods for the determination of stability constants of metal-fulvic acid complexes. Soil Science. 109 (6): 333-340.

Schnitzer, M., and Khan, S.U 1972. Humic substances in the environment. MarcelDekker, New York.

Srilatha, M., 2001. Characterization of humic substances and their interactions with metal ions in relation to their availability to rice. M.Sc.(Ag.) thesis submitted to Acharya N.G. Ranga Agricultural University, Rajendranagar and Hyderabad.

Srilatha, M., 2014. Changes in soil quality, crop productivity and sustainability in rice-rice cropping system under long term fertilizer experiments. Ph.D thesis submitted to Acharya N.G Ranga Agricultural University, Rajendranagar, Hyderabad.

Srilatha, M., Rao, P.C., Sharma, S.H.K and Padmaja, G2013.Physico - chemical characterization of humic substances under long - term application of fertilizers and manures in rice - rice cropping sequence in an Inceptisol. International Journal of Advanced Research.1 (10): 343-348.

Stevenson, F.J., 1982. Humus chemistry-genesis composition and reactions. John Willey and sons, New York.

Stevenson, F.J., 1994. Humus Chemistry: Genesis, Composition, Reaction, Second Edition, John Wiley and Sons, New York.

Stevenson, F.J., Lanath, F.A and Brar, M.S. 1993.
Stability constants of $\mathrm{Cu}$ (II)-humate complexes: comparison of select models. Soil Science. 155 (2): 77-91.

Sujana Reddy, K., 1997. Status and nature of organic matter and its interaction with metal ion in certain alfisols and vertisol of Acharya N.G. Ranga Agricultural University, Rajendranagar Campus Hyderabad. M.Sc. (Ag.) thesis submitted to Acharya N.G. Ranga Agricultural University, Hyderabad.

Sujana Reddy, K., and Rao, P.C. 2000.Characterization of humic-metal ion interactions in alfisols and vertisol by potentiometric methods. Journal of the Indian Society of Soil Science. 48 (3): 596598.

Sujana Reddy, K., Chandrasekhar Rao, P and Sreenivasa Raju, A. 1998.Characterization of humic acid metal ion interactions in an alfisol and vertisol of ANGRAU, Rajendranagar campus by potentiometric methods. Paper presented at $64^{\text {th }}$ Annual Convention of Indian Society of Soil Science at HAU, Hissar, during November 16-19, 1998.

Tahiri, A., Richel, A., Destain, J., Druart, P., Thonart, P and Ongena, M. 2016. Comprehensive comparison of the chemical and structural characterization of landfill leachate and leonardite humic fractions. Anal Boianal Chemistry. 408: 1917-1928.

Tan, K.H., and Van Schuylenborgh, J. 1961. On the organic matter in tropical soils. Nertherland Journal of Agricultural Sciences. 9, 174-180.

Wright, J.R., and Schnitzer, M. 1961. Oxygen containing functional groups in organic matter of a podzol soil. Nature.1402-1463.

\section{How to cite this article:}

Eshwar, M., M. Srilatha, K. Bhanu Rekha and Harish Kumar Sharma, S. 2017. Characterization of Humic Substances by Functional Groups and Spectroscopic Methods. Int.J.Curr.Microbiol.App.Sci. 6(10): 1768-1774. doi: https://doi.org/10.20546/ijcmas.2017.610.213 